\title{
Defective efferocytosis as a predictor of COVID-19 mortality
}

\author{
Adnan EROL, MD. \\ Professor of internal medicine \\ Independent researcher, not affiliated to any institution \\ Silivri-Istanbul, Turkey \\ ORCID ID: https://orcid.org/0000-0002-2741-9755 \\ email: eroladnan@protonmail.com
}

\begin{abstract}
COVID-19 is a generally benign coronavirus disease that can spread rapidly, except for those with a group of risk factors. Since the pathogenesis responsible for the severity of the disease has not been clearly revealed, effective treatment alternatives has not been developed. The hallmark of the SARS-CoV-2-infected cells is apoptosis. Apoptotic cells are cleared through a sterile process defined as efferocytosis by professional and nonprofessional phagocytic cells. The disease would be rapidly brought under control in the organism that can achieve effective efferocytosis, which is also a kind of innate immune response. In the risk group, the efferocytic process is defective. By the addition of the apoptotic cell load associated with SARS-COV-2 infection, failure to achieve efferocytosis of dying cells can initiate secondary necrosis that is a highly destructive process. Uncontrolled inflammation and coagulation abnormalities caused by secondary necrosis reason in various organ failures, lung in particular, which are responsible for the poor prognosis. Following the short and simplified information, this opinion paper aims to present possible treatment options that can control the severity of COVID-19 by detailing the mechanisms that can cause defective efferocytosis.
\end{abstract}

Key words:

Covid-19; Sars-CoV-2; Efferocytosis: Adam17; Phosphatidylserine 
SARS-COV-2-induced COVID-19 pandemic has been caused a serious increase in morbidity and mortality, and devastating problems in the economies of countries. Unprecedented rapid and widespread vaccination has provided significant relief in the control of the pandemic in a short period, less than a year. However, the belief that vaccines can solve everything has brought with it troubles. The dominance of the delta variant, the rapid increase in the number of cases and the rate of hospitalization despite vaccination necessitate taking new measures [1]. People infected with the delta variant of SARSCoV-2 seem to be more likely to spread the virus before developing symptoms. More importantly, there was no difference in the rate of transmission and viral load between vaccinated and unvaccinated people, suggesting that a proportion of vaccinated people can transmit this variant $[2,3]$. It is also a strong possibility that those who have been vaccinated are more contagious because they are asymptomatic or are easily accepted at social events. Moreover, SARS-CoV-2 lambda, a new variant of interest, exhibits higher infectivity and confers resistance to antiviral immunity [4]. At least for these reasons, it seems difficult to control the pandemic with vaccination alone. While COVID-19 is threatening in a certain risk group, it generally shows a moderate course. Therefore, the development of treatment methods that can control the severity and lethality of the disease seems to be the most rational option since the beginning of the pandemic.

\section{SARS-CoV-2 infection and efferocytosis}

SARS-COV-2 is an enveloped virus. Phosphatidylserine (PS) is expressed in the outer leaflet of the viral envelope, with a symmetrical location rather than the asymmetrical phospholipid distribution observed in the normal plasma membrane [5]. As with all enveloped viruses, this facilitates cell entry of SARS-CoV-2 using the apoptotic mimicry pathway [6]. PS receptors (PSRs), Axl in particular, was shown to potentiate the binding and uptake of SARS-COV-2 [6].

SARS-CoV-2 spike protein (S) is divided into two subunits: $\mathrm{S} 1$ unit of $\mathrm{S}$ binds to angiotensinconverting enzyme 2 (ACE2), while 52 mediates membrane fusion. Several arginine residues present in SARS-COV-2 S are cleaved by the host protease, furin that are not found in SARS-CoV-related coronaviruses [7]. Proteolytic processing of SARS-CoV-2 S in the virus producing host cells, rather than during entry into target cells may facilitate subsequent binding to the ACE2 receptors, fusion and entry into target cells [8]. Accordingly, loss of the furin cleavage site has been shown to affect the pathogenesis of SARS-CoV-2, suggesting that the furin cleavage site has a critical role in the transmission of SARS-COV-2 infection [9].

SARS-CoV-2 genome contains 29 open reading frames (ORFs), which encode 29 proteins. One of these, the ORF3a protein is an accessory protein specific to SARS-CoVs. ORF3a is involved in critical steps of the viral infection cycle and determines viral replication and virulence of SARS-CoV-2 [10]. In cells infected with SARS-COV-2, the virus enforces the apoptotic process through ORF3a [11]. ORF3amediated caspase-3 activation initiates both the apoptotic process and a series of changes for the rapid elimination of the apoptotic cell by the phagocytic system:

1. Phospholipase A2 activation increases the level of lysophosphatidylcholine on the outer membrane surface [12].

2. The opening of membrane Pannexin channels causes an increase in extracellular ATP, UTP and spermidine levels [12].

3. An increase in oxidized PS and phosphatidylcholine levels occurs [13]. All of these three pathways act as "find me" signals for the phagocytic cells. 
4. Irreversibly activation of Xkr8, a membrane scramblase, causes PS to be expressed in the membrane outer leaflet, which is the essential "eat me" signal for cells of the phagocytic system [14,15].

In a healthy organism, professional and non-professional phagocytic cells detect "find me" and "eat me" signals and rapidly clear apoptotic cells without damaging the environment through a process known as efferocytosis [16-18]. While macrophages, neutrophils and dendritic cells originating from the bloodstream are professional; local epithelial, endothelial and fibrotic cells are the elements of the nonprofessional phagocytic system [19].

A large number of different PSRs that recognize PS directly and indirectly in phagocytic cells facilitate the functioning of the efferocytosis process $[5,6,14]$. While TIM receptors ( $T$ cell immunoglobulin and mucin domain-containing molecule) provide direct binding, TAM (Tyro3, Axl, and MerTK) receptors indirectly bind to apoptotic cells via mediator molecules such as Gas6 and protein $S$ (ProS) $[5,18]$. Among a number of other PSRs, the importance of the phagocytic cell scavenger receptor CD36 in engulfing the apoptotic cell should be particularly emphasized [20].

Efficient phagocytosis of apoptotic cells, efferocytosis, is one of the most essential components of maintaining tissue homeostasis. After engulfment of the apoptotic cell, phagocytic cells actively control inflammation ("tolerate me") by releasing anti-inflammatory cytokines such as transforming growth factor-beta (TGF- $\beta$ ) and IL-10 [14]. This specialized phagocytosis of apoptotic cells also accelerates the presentation of viral antigens to lymphocytes and T cells, enhancing the activation of antigen-specific $B$ and T cells $[21,22]$.

If the efferocytosis-mediated clearance process is disrupted, the apoptotic cells undergo secondary necrosis. This is highly detrimental process that results in leakage of toxic intracellular antigens, tissue destruction and intensification of the existing inflammation [14,23]. In secondary necrosis, increased neutrophil pro-inflammatory activity and excessive degranulation may cause acute respiratory distress syndrome (ARDS) or multiple organ failure as a result of neutrophil-mediated systemic inflammatory response syndrome $[24,25]$. Membrane rupture due to secondary necrosis triggers the development of a different type of autoimmune response to auto-antigen release with auto-reactive $\mathrm{CD} 4^{+}$cell activation [26]. Thus, efferocytosis, which means rapid and effective noninflammatory and non-immunogenic apoptotic cell clearance through the interrelated "find me", "eat me", and "tolerate me" pathways, performs a unique function in the maintenance of homeostasis at the tissue and system level.

Collectively, COVID-19 patients with a relative healthy premorbid history recover following a mild to moderate course through the functioning of the following mechanisms (Figure 1).

1. SARS-COV-2 replication may lead to the pre-apoptotic changes that would trigger the exposure of normally intracellular anionic phospholipids, PS in particular, on the outer leaflet of the membrane surface of virus-infected cells. These virus-induced apoptotic cells need to be rapidly and efficiently removed otherwise they may produce secondary necrotic debris that promotes the release and hyperactivation of pro-inflammatory molecules from the immune effector cells.

2. Efficient efferocytosis is an essential component of tissue homeostasis and the resolution of inflammation. SARS-CoV-2-infected apoptotic cells expose PS as "eat me" signal, which distinguish them from live cells, initiates efferocytosis by professional and non-professional phagocytic cells in a non-inflammatory manner. After engulfing an apoptotic cell, macrophages actively dampen inflammation by releasing anti-inflammatory cytokines, such as (TGF- $\beta$ ) and interleukin-10, as well as pro-resolving lipid mediators for the resolution of inflammation. 
3. SARS-CoV-2-infected, apoptotic cells are phagocytosed and digested together with virus itself through the actions of degrading enzymes that exist in lysosomes of phagocytes, leading to the inhibition of viral growth. This mode of phagocytic elimination of invading pathogens may be considered to be a cellular innate immune response [27]. Consistently, binding and preventing PS-exposing cells from being phagocytosed by annexin $\mathrm{V}$, which binds specifically to PS, has been reported to augment the rate of mortality among virus-infected mice [28].

4. Under homeostatic conditions, anti-inflammatory cytokines and natural regulatory $T$ cells channel dendritic cell antigen presentation to induce regulatory T-cell differentiation from naïve CD4 ${ }^{+} \mathrm{T}$-cell precursors, and to tolerize effector CD8 ${ }^{+} \mathrm{T}$ cells [29]. Furthermore, efferocytosis of infected apoptotic cells can help to mount an adaptive immune response against virus through the process antigen cross-presentation [30].

Thus, while COVID-19 is highly contagious due to the multibasic furin cleavage site in the $S$ protein [31], it follows a self-limiting course through the operation of the mechanisms briefly described. However, the disease may progress to a more severe and even fatal stage in those with chronic degenerative and cardiovascular diseases, especially in the elderly. If the underlying pathogenesis of this adverse progression could be demonstrated, it may also provide possible target(s) for the treatment.

\section{Risk factors for COVID-19 and defective efferocytosis}

Despite the death of billions of cells every day, effectively functioning efferocytosis maintains normal physiology in the majority of the population; however, it becomes defective in unresolved chronic inflammatory diseases, causing apoptotic cell accumulation [32]. Diseases with increased morbidity and mortality, such as aging, obesity, heart diseases, and diabetes, cause immuno-lipidomic imbalance with lipidome disorder and chronic inflammatory pathologies [33,34]. The characteristic determinants of these disorders are a low-level chronic inflammation and increased apoptotic cell load [35]. Altogether, defective efferocytosis is an essential pathology responsible for the development and progression of chronic inflammatory diseases, including atherosclerosis, obesity, diabetes, heart failure, chronic lung disease, and neurodegenerative disease as well as cancer [36].

The common feature of most of these degenerative chronic disorders is increased ADAM-17 (a disintegrin and metalloproteinase 17) activity in most of the cells, including bronchial epithelial cells, endothelial cells, and phagocytic cells [37,38]. ADAM-17, also known as TNF $\alpha$-converting enzyme (TACE), is a sheddase, capable of proteolytic cleavage and release of membrane-bound molecules [39,40]. Studies revealing the relationship between ADAM-17 and a group of inflammatory degenerative diseases, including cancer, are reported with increasing frequency. Interestingly, transcriptional ADAM-17 protein expression has been observed to increase in diabetic subjects through the hyperglycemia-induced HIF-1 activity [41,42]. In addition, the euglycemic effect of insulin restored ACE2 and ADAM-17 expression back to the physiological levels [41], suggesting that insulin may work as an ADAM17 inhibitor [43]. Furthermore, evidence is provided that ADAM-17 plays a role in metabolic syndrome-related pathologies $[44,45]$. On the other hand, some clear data also show the possible relationship between the presence of metabolic syndrome and the severity of COVID-19 [46]. Accordingly, several of the features of the metabolic syndrome seem to be associated with a worse prognosis in patients with COVID-19 [47].

ADAM-17 is the main secretase responsible for ectodomain shedding of most of the cell surface and of the transmembrane proteins. At least 90 substrates are processed by ADAM-17. Its activity towards TNF $\alpha$ and IL-6R $\alpha$ could potentiate the proinflammatory effects of the cytokines [48]. In addition, ADAM-17 activity promotes lymphocyte and neutrophil translocation to the inflammatory 
sites [49]. Taken together, premorbid patients with increased ADAM17 and thus pro-inflammatory activity, if contracted SARS-CoV-2 infection, would have the inflammatory process more severe [50].

PS translocation to the membrane surface, an exclusive marker of apoptosis, is also required for the sheddase function of ADAM-17. The externalized PS in the membrane interacts electrostatically with ADAM-17 and then enables substrate processing to take place [51]. Signaling pathways destined to activate ADAM-17-sheddase function converge at a final step leading to scramblase activation with breakdown of phospholipid asymmetry and exposure of PS at the outer leaflet [52]. On the other hand, PS surface exposure is required for the regulation of cholesterol metabolism, inflammation, and hemostasis [53]. Recalling that anti-inflammatory cytokines are secreted during PS-induced efferocytosis, it is possible to consider this as an effort to control the existing inflammatory pathology [54]. Therefore, exposure of PS on the outer plasma membrane is increased in chronic inflammatory disorders, including atherosclerotic diseases and diseases associated with coagulation disorders [53][55], which may potentiate the activity of ADAM-17.

In principle, all natural membranes may function as a procoagulant phospholipid surface, if sufficient PS is present in the exofacial leaflet [56]. Microparticles and microvesicles refer to large extracellular vesicles, which are small membranous structures [57]. Microparticles are present in blood of healthy individuals, but their number is considerably increased in diseased states such as inflammation, cardiovascular events, and cancer, where they may contribute to the increased risk of thrombotic events in these patients [56]. Circulating microparticles are shed from the plasma membrane of a variety of cells, including platelets, erythrocytes, leukocytes, endothelial cells, and tumor cells as a result of activation and/or apoptosis $[56,58]$. These microparticles have lost lipid asymmetry and expose PS, thus providing a procoagulant surface [56]. The prothrombotic state mediated by PS-exposing microparticles is implicated in the adverse progression of chronic inflammatory diseases, including atherosclerosis [53]. In addition, ADAM-17 was shown to present in microparticles released from activated cells; thus, ADAM17 activity can be distributed to more distant cells [59]. Remarkably, increased levels of microparticles in the circulation of severe COVID-19 patients that trigger the risk of thromboembolic complications were reported [60]. Furthermore, the level of PS-exposing microparticles correlated more strongly with severity of COVID-19 than indices such as lymphopenia, IL-6, D-Dimer, fibrinogen, and other established laboratory parameters [61].

ACE2, a metallopeptidase and a key component of renin-angiotensin system (RAS), is the main receptor for the cellular entry of SARS-COV and SARS-CoV-2. Binding of SARS viruses to ACE2 triggers the viral conformational changes, which may increase the proteolytic digestion between the S1 and S2 subunits [62,63]. Indeed, ACE2 cleavage by ADAM-17 is required for efficient SARS-S-driven entry. Furthermore, ADAM-17-mediated shedding of ACE2 results in the release of the ectodomain into the circulation, which preserves its catalytic and bioactive potency, and the binding site for SARS-COV-2 [64]. Recent studies demonstrated that ADAM-17-driven soluble ACE2 (SACE2) levels are elevated in COVID-19 patients. The binding of SARS-COV-2 by SACE2 may enable cell entry of tissues where membrane-bound ACE2 (mACE2) is poorly expressed $[65,66]$. Low expression levels of mACE2 and associated higher ADAM17 activity have been related with cardiovascular diseases. Consequently, the activity of the SACE2 is increased in patients with cardiovascular disease and hypertension, which correlates with the severity of the disease [67]. Thus, chronic diseases with increased membrane PS exposure and associated ADAM-17 activity may adversely affect the prognosis of the COVID-19 through the facilitated cellular virus entry as a result of the increased SACE2 levels [50,65].

PSRs, including TIM1, TAM, and CD36, can also be proteolytically cleaved by the transmembrane protease ADAM-17 $[20,68]$. This shedding can prevent receptor functions in macrophage-mediated apoptotic cell engulfment [69]. The soluble cleavage products may function as sequester ligands and decoy receptors, which can act as an antagonist for those PSRs [69] [70]. Accordingly, deletion of ADAM17 has been shown to increase macrophage-mediated efferocytosis in vivo, resulting in an enhanced anti-inflammatory response [71]. 
Programmed cell death 1 (PD-1), a surface molecule and a member of the immunoglobulin superfamily, functions as co-inhibitory receptors during immune responses against pathogens and cancer. Hence, PD-1 is important in the regulation of the magnitude and quality of T cell response [72]. PD-1 interacts with the ligands PD-L1 and PD-L2. PD-L1 is expressed in all hematopoietic cells and also by many non-hematopoietic cell types such as endothelial and epithelial cells. PD-L2 expression, on the other hand, is limited to hematopoietic cells such as dendritic cells, B cells, and monocytes/macrophages $[72,73]$. During the acute phase of virus infection, stimulation of PD-1/PD-L1 signaling pathway modulates the strength and quality of cytotoxic $C D 8^{+} T$ cell attack, maintaining a balance between virus elimination and tissue damage [72].

ADAM17 can cleave PD-L1 from the surface of vesicles and cells [74]. Despite circulating soluble PD-L1 (SPD-L1) has been largely known as a prognostic biomarker for cancers [75], SPD-L1 has also been detected in various pathologies, often associated with markers of inflammation [76]. Of note, the recent study suggests that an increase in SPD-L1 may be a sign of poor prognosis as a result of dysregulation of the PD-1/PD-L1 axis in COVID-19 patients [77].

To summarize, following mechanisms due to the increased PS exposure and ADAM-17 activity adversely affect the prognosis of the disease in those who have comorbidities along with the COVID-19 disease (Figure 2).

1. The proinflammatory burden that will determine the severity of COVID-19 is already at high levels before the onset of the disease.

2. ACE2 cleavage and SACE2 levels are increased. The facilitated extracellular association between SACE2 and SARS-COV-2 may reinforce the infection more widespread and devastating.

3. Circulating microparticles have been implicated in cellular signaling processes in immune responses, inflammation, and coagulation. In addition to PS exposure on their membrane, they may contain ADAM17, which can contribute to substrate shedding on more distant cells [59].

4. Loss of PS receptors on phagocytic cells (efferocytes) impairs the recognition and engulfment process of apoptotic cells, thereby impairing efferocytosis.

5. Lastly, decreased expression of PD-L1 on T cells may reflect the induction of a hyperactivation status which may cause an excessive immunopathology.

Collectively, potentiated dysregulation of ADAM-17 activity may lead to the chronic operation of defective efferocytosis. In turn, defective efferocytosis accompanying in a number of non-resolving, chronic inflammatory diseases may lead to accumulation of dead cells. The dead cells can become secondarily necrotic, which can lead to tissue necrosis, autoimmunity, and pathological inflammation. Thus, defective efferocytosis is emerging as a key mechanism driving the development and progression of chronic inflammatory diseases, including atherosclerosis, obesity, diabetes, heart failure, chronic lung disease, neurodegenerative disease, and cancer [36].

\section{Defective efferocytosis and COVID-19 severity}

Efferocytosis is a mechanism for eliminating pathogens and pathogen-infected cells in an immunologically silent manner. The quality for efferocytic clearance of virus and virus-infected apoptotic cells depends on the virus load and the operation of efferocytic machinery [17]. Therefore, increased viral load and defect in efferocytic cells seem to be the crucially important factors that will determine the prognosis of the disease. Patients in the risk group who already have problems in apoptotic cell clearance due to defective efferocytosis cannot cope with the additional acute apoptotic burden that occurs with COVID-19 disease. Consequently, the intractable inflammation that increases with secondary necrosis causes destruction and inevitable organ failure. Support for this approach came from a recent study showing that dysfunctional efferocytosis is the leading cause of the increased inflammatory response and widespread tissue damage seen in COVID-19 [78]. 
Older age, obesity, diabetes, cardiovascular diseases, and active cancer have each been found to be independently associated with a higher mortality risk for COVID-19 [79]. Furthermore, COVID-19 does not spare young people as well. The majority of comorbidities that play a role in the prognosis of the elderly have also been shown as risk factors that may be responsible for the severity of COVID-19 for the young adult population aged $16-28$ years [80].

\section{Novel treatment options targeting defective efferocytosis in COVID-19}

The clinical trial research has occurred at an unprecedented pace during COVID-19 pandemic. Among the many potential treatment options for COVID-19, only a few have been shown to be effective and predictable for the clinical treatment of patients. Some immunomodulatory drugs such as anti-TNF, anti-IL-1, anti-IL-6 used in COVID-19 patients have been shown to support recovery, possibly by neutralizing the increased cytokine levels by the augmented ADAM17 activity. [81]. In a study showing the effect of glucocorticoids, another group of immune modulators, dexamethasone treatment in hospitalized COVID-19 patients provided a lower mortality among those requiring respiratory support [82].

Glucocorticoids are powerful anti-inflammatory agents by their ability to inhibit the recruitment of inflammatory cells and to downregulate proinflammatory cytokine expression [83]. Glucocorticoids have been shown to modulate the expression of over 100 genes, including those known to be associated with efferocytosis, such as Mer tyrosine kinase (MerTK), a member of TAM family PS receptors [84]. Dexamethasone was also shown to promote the expression of two PS-binding opsonins, protein S and MFG-E8, which facilitate MerTK-dependent efferocytosis of apoptotic cells $[83,85]$. Thus, corticosterones, which provide a limited support to defective efferocytosis, find wide use in clinical treatment as an effective drug that can control the severity of cases.

Peroxisome proliferator-activated receptor $\gamma$ (PPAR $\gamma$ ) agonists such as pioglitazone alter cellular metabolism of liver, adipose tissue, and muscle cells as well as inflammatory macrophages. In addition, they have many anti-inflammatory effects including the suppression of Th1 and Th17-induced inflammation, inhibition of NFKB, and upregulation of IL-10 [86,87]. Interestingly, PPAR $\gamma$ agonists enhance MerTK and opsonin expression by human macrophages, similar to glucocorticoids [88]. Furthermore, treatment with pioglitazone, either prophylactically or during inflammation, while significantly enhances PPAR $\gamma$-mediated programming of efferocytes, reduces accumulation of apoptotic cells $[86,89]$. Therefore, low dose pioglitazone alone or combination with glucocorticoids seems to be a readily available inexpensive and effective treatment option for the correction of defective efferocytosis $[87,90]$.

While ADAM-17 plays a crucial role in the pathogenesis of defective efferocytosis, it was shown that ADAM-17 activity is also important in the development and worse prognosis of COVID-19 [91]. Therefore, inhibiting ADAM-17 activity seems to be a rational option in severe cases of COVID-19. Experimental evidence has been shown that the inhibition of ADAM-17 protects against lung inflammation by reducing cytokine storm and excessive neutrophil recruitment to the lung in a mouse model associated with COVID-19 [92]. However, ADAM-17 has a broad regulatory role in human biological processes. Consistently, dramatic disorders affecting the intestines, lungs, eyes, and hair of ADAM-17-deficient mice and humans have prompted caution regarding therapeutic interventions for ADAM-17 blockade in humans $[93,94]$. Nevertheless, researchers are nowadays focusing in developing strategies for a selective inhibition of ADAM-17. Several compounds have recently entered into clinical trials, but have been withdrawn due to emerging adverse events [91]. Therefore, despite the central importance of ADAM-17 in the pathogenesis of the disease, the option of inhibiting ADAM-17 in severe cases of COVID-19 should be viewed with caution. 
It has been emphasized above that the level of SACE2 in the circulation increases due to defective efferocytosis in diseases that constitute a risk group for COVID-19. However, another therapeutic approach proposes using SACE2 to trap and neutralize SARS-CoV-2. According to this perspective, while mACE2 may mediate cell entry of SARS-CoV-2, a genetically modified soluble form of ACE2, called human recombinant soluble angiotensin-converting enzyme-2 (hrSACE2), may decrease cell entry of SARS-CoV-2 competing for mACE2 [95]. However, the plasma RAS balance in COVID-19 patients was already characterized by a strong transient increase in circulating plasma SACE2 [66]. Therefore, in COVID19 patients with comorbid diseases, both Angiotensin II and virus adversely affect the prognosis by affecting the RAS balance in a way that down-regulates ACE2 [96]. Interestingly, recent study reports encouraging results in the first severe COVID-19 patient treated with hrSACE2 [97]. However, SACE2 concentrations used in experimental studies are much higher $(\mu \mathrm{g} / \mathrm{ml})$ than the physiological range of SACE2 concentrations $(\eta \mathrm{g} / \mathrm{ml})$. While high range of SACE2 concentrations can compete with the SARSCOV-2-ACE2 complex for cell entry, physiological range of SACE2 may facilitate virus entry and thus SARSCoV-2 infectivity. Therefore, treatment that may alter SACE2 levels in physiological range in patients with COVID-19 should be carefully considered [65].

In severe cases of COVID-19 where defective efferocytosis is essential in the pathogenesis, the characteristic feature of infected-apoptotic cells waiting to be cleared are that they express PS on the outer surface of the membrane. Therefore, triggering antibody-dependent cellular phagocytosis (ADCP) with PS-specific antibodies can be considered as an important alternative for the treatment of such pathologies in which PS receptors are deficient. In fact, the possibility of such specific monoclonal antibody already exists. Bavituximab (PGN401) is a monoclonal human-mouse chimeric antibody directed against the membrane phospholipid PS. Bavituximab and other antibodies that target PS were developed by Philip Thorpe's laboratory to specifically target tumor vasculature [15,98]. Bavituximab does not bind PS directly. It binds to PS-expressing membranes by crosslinking two molecules of $\beta 2$ glycoprotein 1 ( $\beta 2 \mathrm{GP1}$ ) bound to PS on the membrane [14,99]. Bavituximab could be expected to act by at least two mechanisms in severe COVID-19 patients: i) it can reduce the amount of virus to infect other tissues as a result of opsonization-mediated clearance of SARS-COV2; ii) it induces ADCP of virusinfected apoptotic cells; thus, in pathologies where efferocytosis is defective, an opportunity arises for clearing apoptotic cells [100].

$\beta 2$ GP1 is an evolutionarily conserved single chain anionic phospholipid-binding glycoprotein. It has gained much attention since the discovery of its role in antiphospholipid syndrome (APS) [101]. Accordingly, $\beta 2 \mathrm{GP} 1$ binds to the PS expressed on apoptotic cells. When the amount of $\beta 2 \mathrm{GP} 1$ bound to PS reaches a certain threshold, antibodies dimerize the adjacent $\beta 2 \mathrm{GP1}$ molecules. Consequently, this high affinity anti- $\beta 2$ GP1- $\beta 2$ GP1 complexes may activate targeted cells, causing anti-phospholipid antibodies-related manifestations [102]. However, during the clinical trials, bavituximab therapy appeared safe and well tolerated, and reductions were observed in virus load in the blood. Furthermore, coagulation parameters remained within the normal range $[100,103]$. In the light of those data and considering the FDA approval of the drug, I had planned a clinical trial to investigate the efficacy of bavituximab treatment in patients with severe COVID-19 in October 2020. Unfortunately, the opinion remained in theory, as OncXerna, the company that owns the drug, did not welcome this offer. Since the hallmark autoantibodies of APS are anti-beta2 glycoprotein, a series of fully human PS-targeting antibodies was generated by phage display technology [104]. To further explore the antiviral activity of PS-targeting antibodies, my efforts to develop a specific antibody in my country, such as PGN632, that could bind directly to PS and would not need the cofactor $\beta 2$ GP1 protein [103], were also failed.

The majority of those who are infected with COVID-19 have a self-limiting infection and do recover. However, a minority with comorbidities proceeds to more severe disease, requiring intensive care unit admission [105]. Therefore, the disease may cease to be a threat following the treatment of patients who are in the risk group or whose condition deteriorates with the monoclonal anti-PS antibody to be developed. Moreover, such a treatment would also have the potential to control the 
morbidity and mortality caused by other enveloped viruses such as influenza, ebola, dengue and even HIV.

Vaccine and therapeutic development are predominantly focused on the essential virus-encoded Spike protein. However, the variation of the $S$ gene between SARS-like CoV viruses and SARS-CoV-2 variants may affect the efficacy and particularly for cross-protection of a vaccine. Nowadays when mutations against vaccines are confusing, other proteins of SARS-COV-2 seem to be important targets to develop alternative treatments against potential resistance or emerging new viruses in the future [106]. SARS-COV-2 ORF3a is a putative viral ion channel implicated in autophagy inhibition, inflammasome activation, and apoptosis. As explained above, it is a specific viral protein that may be responsible for the development of the virus-induced apoptotic load and ultimately the adverse course of the disease in cases of defective efferocytosis.

SARS-CoV-2 enters the host cell by both membrane fusion and by clathrin/caveolin-mediated endocytosis after binding to the ACE2 cell-surface receptors [107]. Caveolin-1 is a major component of caveolae membrane microdomains, which are involved in non-clathrin-mediated virus uptake into cells [108]. Viral ORF3a protein binding to host caveolin-1 was shown to be essential for entry and endomembrane trafficking of SARS-CoV-2. In addition to viral entry, caveolin-1 was also associated with all stages of viral life cycle $[107,108]$. Even if ORF3a is expressed on viral particles, anti-ORF3a antibodies will not neutralize the virus by preventing attachment or fusion [109]. In other words, antibodies that bind to ORF3a while disrupting the functions of the protein, the antibody-bound virus would be able to enter the cell. In turn, entry of antibody bound virus into the cell may present an opportunity for an unusual cytosolic antibody receptor, called TRIM21. Critically, TRIM21 is also a ubiquitin ligase and is able to efficiently target antibody-bound substrates for proteasomal degradation [110]. Therefore, the development of antibody or vaccine, targeting ORF3a, may provide more effective results in controlling severe cases of COVID-19 with a high risk of mortality.

In full agreement with K. Kunzelmann, "A drug is urgently needed, as it becomes more and more obvious that vaccination alone might not sufficient to curb the pandemic caused by this rapidly mutating virus" [111]. Therefore, we will be awaiting further research in the hope that this work will be evaluated to respond to this urgent need.

\section{Conflict of Interests}

There is no conflict of interest 


\section{References}

1. Brown CM, Vostok J, Johnson H, Burns M, Gharpure R, Sami S, et al. Outbreak of SARS-CoV-2 Infections, Including COVID-19 Vaccine Breakthrough Infections, Associated with Large Public Gatherings - Barnstable County, Massachusetts, July 2021. MMWR Morb Mortal Wkly Rep [Internet]. 2021;70:1059-62. Available from: http://www.cdc.gov/mmwr/volumes/70/wr/mm7031e2.htm?s_cid=mm7031e2_w 2. Kasen K. Riemersma, Brittany E. Grogan, Amanda Kita-Yarbro, Gunnar E. Jeppson, David H. O'Connor, Thomas C. Friedrich KMG. Shedding of Infectious SARS-CoV-2 Despite Vaccination when the Delta Variant is Prevalent - Wisconsin, July 2021. Prepr medRxiv. 2021; Doi:10.1101/2021.07.31.21261387

3. Musser JM et al. Delta variants of SARS-CoV-2 cause significantly increased vaccine breakthrough COVID-19 cases in Houston, Texas. Prepr medRxiv. 2021; Doi: 10.1101/2021.07.19.21260808 4. Kimura I et al. SARS-CoV-2 Lambda variant exhibits higher infectivity and immune resistance. Prepr bioRxiv. 2021; Doi: 10.1101/2021.07.28.454085

5. Evans JP, Liu S-L. Role of host factors in SARS-CoV-2 entry. J Biol Chem [Internet]. 2021;297:100847. Available from: https://linkinghub.elsevier.com/retrieve/pii/S0021925821006451

6. Bohan D et al. No TitlPhosphatidylserine Receptors Enhance SARS-CoV-2 Infection: AXL as a Therapeutic Target for COVID-19e. Prepr bioRxiv. 2021; Doi: 10.1101/2021.06.15.448419

7. Hoffmann M, Kleine-Weber H, Pöhlmann S. A Multibasic Cleavage Site in the Spike Protein of SARSCoV-2 Is Essential for Infection of Human Lung Cells. Mol Cell [Internet]. 2020;78:779-784.e5. Available from: https://linkinghub.elsevier.com/retrieve/pii/S1097276520302641

8. Shang J, Wan Y, Luo C, Ye G, Geng Q, Auerbach A, et al. Cell entry mechanisms of SARS-CoV-2. Proc Natl Acad Sci [Internet]. 2020;117:11727-34. Available from:

http://www.pnas.org/lookup/doi/10.1073/pnas.2003138117

9. Johnson BA, Xie X, Bailey AL, Kalveram B, Lokugamage KG, Muruato A, et al. Loss of furin cleavage site attenuates SARS-CoV-2 pathogenesis. Nature [Internet]. 2021;591:293-9. Available from: http://www.nature.com/articles/s41586-021-03237-4

10. Azad GK, Khan PK. Variations in Orf3a protein of SARS-CoV-2 alter its structure and function. Biochem Biophys Reports [Internet]. 2021;26:100933. Available from: https://linkinghub.elsevier.com/retrieve/pii/S2405580821000273

11. Ren Y, Shu T, Wu D, Mu J, Wang C, Huang M, et al. The ORF3a protein of SARS-CoV-2 induces apoptosis in cells. Cell Mol Immunol [Internet]. 2020;17:881-3. Available from:

http://www.nature.com/articles/s41423-020-0485-9

12. Narahari AK, Kreutzberger AJ, Gaete PS, Chiu Y-H, Leonhardt SA, Medina CB, et al. ATP and large signaling metabolites flux through caspase-activated Pannexin 1 channels. Elife [Internet]. 2021;10. Available from: https://elifesciences.org/articles/64787

13. Yamashita A, Morikawa H, Tajima N, Teraoka M, Kusumoto C, Nakaso K, et al. Mechanisms underlying production and externalization of oxidized phosphatidylserine in apoptosis: involvement of mitochondria. Yonago Acta Med [Internet]. 2012;55:11-20. Available from:

http://www.ncbi.nlm.nih.gov/pubmed/24031135

14. Birge RB, Boeltz S, Kumar S, Carlson J, Wanderley J, Calianese D, et al. Phosphatidylserine is a global immunosuppressive signal in efferocytosis, infectious disease, and cancer. Cell Death Differ [Internet]. 2016;23:962-78. Available from: http://www.nature.com/articles/cdd201611

15. Dayoub AS, Brekken RA. TIMs, TAMs, and PS- antibody targeting: implications for cancer immunotherapy. Cell Commun Signal [Internet]. 2020;18:29. Available from: https://biosignaling.biomedcentral.com/articles/10.1186/s12964-020-0521-5 16. Kumar S, Calianese D, Birge RB. Efferocytosis of dying cells differentially modulate immunological outcomes in tumor microenvironment. Immunol Rev [Internet]. 2017;280:149-64. Available from: 
https://onlinelibrary.wiley.com/doi/10.1111/imr.12587

17. Karaji N, Sattentau QJ. Efferocytosis of Pathogen-Infected Cells. Front Immunol [Internet]. 2017;8.

Available from: http://journal.frontiersin.org/article/10.3389/fimmu.2017.01863/full

18. Calianese DC, Birge RB. Biology of phosphatidylserine (PS): basic physiology and implications in immunology, infectious disease, and cancer. Cell Commun Signal [Internet]. 2020;18:41. Available from: https://biosignaling.biomedcentral.com/articles/10.1186/s12964-020-00543-8

19. Serizier SB, McCall K. Scrambled Eggs: Apoptotic Cell Clearance by Non-Professional Phagocytes in the Drosophila Ovary. Front Immunol [Internet]. 2017;8. Available from:

http://journal.frontiersin.org/article/10.3389/fimmu.2017.01642/full

20. Moller-Tank S, Maury W. Phosphatidylserine receptors: Enhancers of enveloped virus entry and infection. Virology [Internet]. 2014;468-470:565-80. Available from:

https://linkinghub.elsevier.com/retrieve/pii/S0042682214004206

21. Albert ML, Sauter B, Bhardwaj N. Dendritic cells acquire antigen from apoptotic cells and induce class I-restricted CTLs. Nature [Internet]. 1998;392:86-9. Available from:

http://www.nature.com/articles/32183

22. Moyer TJ, Zmolek AC, Irvine DJ. Beyond antigens and adjuvants: formulating future vaccines. J Clin Invest [Internet]. 2016;126:799-808. Available from: https://www.jci.org/articles/view/81083

23. Silva MT. Secondary necrosis: The natural outcome of the complete apoptotic program. FEBS Lett [Internet]. 2010;584:4491-9. Available from: http://doi.wiley.com/10.1016/j.febslet.2010.10.046

24. Laforge M, Elbim C, Frère C, Hémadi M, Massaad C, Nuss $P$, et al. Tissue damage from neutrophilinduced oxidative stress in COVID-19. Nat Rev Immunol [Internet]. 2020;20:515-6. Available from: http://www.nature.com/articles/s41577-020-0407-1

25. Wang J, Li Q, Yin Y, Zhang Y, Cao Y, Lin X, et al. Excessive Neutrophils and Neutrophil Extracellular Traps in COVID-19. Front Immunol [Internet]. 2020;11. Available from:

https://www.frontiersin.org/article/10.3389/fimmu.2020.02063/full

26. Sachet M, Liang YY, Oehler R. The immune response to secondary necrotic cells. Apoptosis [Internet]. 2017;22:1189-204. Available from: http://link.springer.com/10.1007/s10495-017-1413-z

27. Hashimoto Y, Moki T, Takizawa T, Shiratsuchi A, Nakanishi Y. Evidence for Phagocytosis of Influenza Virus-Infected, Apoptotic Cells by Neutrophils and Macrophages in Mice. J Immunol [Internet]. 2007;178:2448-57. Available from: http://www.jimmunol.org/lookup/doi/10.4049/jimmunol.178.4.2448 28. Watanabe Y, Hashimoto Y, Shiratsuchi A, Takizawa T, Nakanishi Y. Augmentation of fatality of influenza in mice by inhibition of phagocytosis. Biochem Biophys Res Commun [Internet]. 2005;337:8816. Available from: https://linkinghub.elsevier.com/retrieve/pii/S0006291X05021327

29. Tian L, Choi S-C, Lee H-N, Murakami Y, Qi C-F, Sengottuvelu M, et al. Enhanced efferocytosis by dendritic cells underlies memory T-cell expansion and susceptibility to autoimmune disease in CD300fdeficient mice. Cell Death Differ [Internet]. 2016;23:1086-96. Available from:

http://www.nature.com/articles/cdd2015161

30. Cho K-J, Ishido S, Eisenlohr LC, Roche PA. Activation of Dendritic Cells Alters the Mechanism of MHC Class II Antigen Presentation to CD4 T Cells. J Immunol [Internet]. 2020;204:1621-9. Available from: http://www.jimmunol.org/lookup/doi/10.4049/jimmunol.1901234

31. Wrobel AG, Benton DJ, Xu P, Roustan C, Martin SR, Rosenthal PB, et al. SARS-CoV-2 and bat RaTG13 spike glycoprotein structures inform on virus evolution and furin-cleavage effects. Nat Struct Mol Biol [Internet]. 2020;27:763-7. Available from: http://www.nature.com/articles/s41594-020-0468-7

32. Yurdagul A, Doran AC, Cai B, Fredman G, Tabas IA. Mechanisms and Consequences of Defective Efferocytosis in Atherosclerosis. Front Cardiovasc Med [Internet]. 2018;4. Available from:

http://journal.frontiersin.org/article/10.3389/fcvm.2017.00086/full

33. Schwarz B, Sharma L, Roberts L, Peng X, Bermejo S, Leighton I, et al. Cutting Edge: Severe SARS-

CoV-2 Infection in Humans Is Defined by a Shift in the Serum Lipidome, Resulting in Dysregulation of Eicosanoid Immune Mediators. J Immunol [Internet]. 2021;206:329-34. Available from: 
http://www.jimmunol.org/lookup/doi/10.4049/jimmunol.2001025

34. Arienti S, Barth ND, Dorward DA, Rossi AG, Dransfield I. Regulation of Apoptotic Cell Clearance During Resolution of Inflammation. Front Pharmacol [Internet]. 2019;10. Available from:

https://www.frontiersin.org/article/10.3389/fphar.2019.00891/full

35. Sendama W. The effect of ageing on the resolution of inflammation. Ageing Res Rev [Internet].

2020;57:101000. Available from: https://linkinghub.elsevier.com/retrieve/pii/S1568163719303733

36. Doran AC, Yurdagul A, Tabas I. Efferocytosis in health and disease. Nat Rev Immunol [Internet].

2020;20:254-67. Available from: http://www.nature.com/articles/s41577-019-0240-6

37. Gooz M. ADAM-17: the enzyme that does it all. Crit Rev Biochem Mol Biol [Internet]. 2010;45:146-69.

Available from: http://www.tandfonline.com/doi/full/10.3109/10409231003628015

38. Shalaby L, Thounaojam M, Tawfik A, Li J, Hussein K, Jahng WJ, et al. Role of Endothelial ADAM17 in

Early Vascular Changes Associated with Diabetic Retinopathy. J Clin Med [Internet]. 2020;9:400. Available from: https://www.mdpi.com/2077-0383/9/2/400

39. Black RA, Rauch CT, Kozlosky CJ, Peschon JJ, Slack JL, Wolfson MF, et al. A metalloproteinase

disintegrin that releases tumour-necrosis factor- $\alpha$ from cells. Nature [Internet]. 1997;385:729-33.

Available from: http://www.nature.com/articles/385729a0

40. Patel VB, Clarke N, Wang Z, Fan D, Parajuli N, Basu R, et al. Angiotensin II induced proteolytic

cleavage of myocardial ACE2 is mediated by TACE/ADAM-17: A positive feedback mechanism in the RAS.

J Mol Cell Cardiol [Internet]. 2014;66:167-76. Available from:

https://linkinghub.elsevier.com/retrieve/pii/S0022282813003507

41. Salem ESB, Grobe N, Elased KM. Insulin treatment attenuates renal ADAM17 and ACE2 shedding in

diabetic Akita mice. Am J Physiol Physiol [Internet]. 2014;306:F629-39. Available from:

https://www.physiology.org/doi/10.1152/ajprenal.00516.2013

42. Li R, Uttarwar L, Gao B, Charbonneau M, Shi Y, Chan JSD, et al. High Glucose Up-regulates ADAM17 through HIF-1 $\alpha$ in Mesangial Cells. J Biol Chem [Internet]. 2015;290:21603-14. Available from:

https://linkinghub.elsevier.com/retrieve/pii/S0021925820449245

43. Stepanova G. Biologia Futura: is ADAM 17 the reason for COVID-19 susceptibility in hyperglycemic

and diabetic patients? Biol Futur [Internet]. 2021;72:291-7. Available from:

https://link.springer.com/10.1007/s42977-021-00092-2

44. Menghini R, Fiorentino L, Casagrande V, Lauro R, Federici M. The role of ADAM17 in metabolic

inflammation. Atherosclerosis [Internet]. 2013;228:12-7. Available from:

https://linkinghub.elsevier.com/retrieve/pii/S0021915013000609

45. Matthews J, Villescas S, Herat L, Schlaich M, Matthews V. Implications of ADAM17 activation for hyperglycaemia, obesity and type 2 diabetes. Biosci Rep [Internet]. 2021;41. Available from:

https://portlandpress.com/bioscirep/article/41/5/BSR20210029/228464/Implications-of-ADAM17-

activation-for

46. le Roux CW. COVID-19 alters thinking and management in metabolic diseases. Nat Rev Endocrinol

[Internet]. 2021;17:71-2. Available from: http://www.nature.com/articles/s41574-020-00449-y

47. Finucane FM, Davenport C. Coronavirus and Obesity: Could Insulin Resistance Mediate the Severity of

Covid-19 Infection? Front Public Heal [Internet]. 2020;8. Available from:

https://Www.frontiersin.org/article/10.3389/fpubh.2020.00184/full

48. Yang G, Cui $M$, Jiang $W$, Sheng J, Yang $Y$, Zhang $X$. Molecular switch in human diseases-disintegrin

and metalloproteinases, ADAM17. Aging (Albany NY) [Internet]. 2021;13:16859-72. Available from:

https://www.aging-us.com/lookup/doi/10.18632/aging.203200

49. Wang Y, Herrera AH, Li Y, Belani KK, Walcheck B. Regulation of Mature ADAM17 by Redox Agents for

L-Selectin Shedding. J Immunol [Internet]. 2009;182:2449-57. Available from:

http://www.jimmunol.org/lookup/doi/10.4049/jimmunol.0802770

50. Zipeto D, Palmeira J da F, Argañaraz GA, Argañaraz ER. ACE2/ADAM17/TMPRSS2 Interplay May Be the Main Risk Factor for COVID-19. Front Immunol [Internet]. 2020;11. Available from: 
https://www.frontiersin.org/article/10.3389/fimmu.2020.576745/full

51. Sommer A, Bhakdi S, Reiss K. How membrane asymmetry regulates ADAM17 sheddase function. Cell Cycle [Internet]. 2016;15:2995-6. Available from:

https://www.tandfonline.com/doi/full/10.1080/15384101.2016.1211449

52. Reiss K, Bhakdi S. The plasma membrane: Penultimate regulator of ADAM sheddase function. Biochim Biophys Acta - Mol Cell Res [Internet]. 2017;1864:2082-7. Available from:

https://linkinghub.elsevier.com/retrieve/pii/S0167488917301581

53. Darabi M, Kontush A. Phosphatidylserine in atherosclerosis. Curr Opin Lipidol [Internet]. 2016;27:414-

20. Available from: http://journals.lww.com/00041433-201608000-00014

54. Harel-Adar T, Mordechai T Ben, Amsalem Y, Feinberg MS, Leor J, Cohen S. Modulation of cardiac

macrophages by phosphatidylserine-presenting liposomes improves infarct repair. Proc Natl Acad Sci [Internet]. 2011;108:1827-32. Available from:

http://www.pnas.org/lookup/doi/10.1073/pnas.1015623108

55. Kawai T, Elliott KJ, Scalia R, Eguchi S. Contribution of ADAM17 and related ADAMs in cardiovascular diseases. Cell Mol Life Sci [Internet]. 2021;78:4161-87. Available from:

https://link.springer.com/10.1007/s00018-021-03779-w

56. Bevers EM, Williamson PL. Getting to the Outer Leaflet: Physiology of Phosphatidylserine Exposure at the Plasma Membrane. Physiol Rev [Internet]. 2016;96:605-45. Available from:

https://www.physiology.org/doi/10.1152/physrev.00020.2015

57. Morel O, Jesel L, Freyssinet J-M, Toti F. Cellular Mechanisms Underlying the Formation of Circulating

Microparticles. Arterioscler Thromb Vasc Biol [Internet]. 2011;31:15-26. Available from:

https://www.ahajournals.org/doi/10.1161/ATVBAHA.109.200956

58. Owens AP, Mackman N. Microparticles in Hemostasis and Thrombosis. Weber C, Mause S, editors.

Circ Res [Internet]. 2011;108:1284-97. Available from:

https://www.ahajournals.org/doi/10.1161/CIRCRESAHA.110.233056

59. Groth E, Pruessmeyer J, Babendreyer A, Schumacher J, Pasqualon T, Dreymueller D, et al. Stimulated release and functional activity of surface expressed metalloproteinase ADAM17 in exosomes. Biochim Biophys Acta - Mol Cell Res [Internet]. 2016;1863:2795-808. Available from:

https://linkinghub.elsevier.com/retrieve/pii/S0167488916302221

60. Cappellano G, Raineri D, Rolla R, Giordano M, Puricelli C, Vilardo B, et al. Circulating Platelet-Derived Extracellular Vesicles Are a Hallmark of Sars-Cov-2 Infection. Cells [Internet]. 2021;10:85. Available from: https://www.mdpi.com/2073-4409/10/1/85

61. Rausch $L$, et al. Binding of phosphatidylserine-positive microparticles by PBMCs classifies disease severity in COVID-19 patients, bioRxiv Prepr. Doi: 10.1101/2021.06.18.448935

62. Heurich A, Hofmann-Winkler H, Gierer S, Liepold T, Jahn O, Pohlmann S. TMPRSS2 and ADAM17 Cleave ACE2 Differentially and Only Proteolysis by TMPRSS2 Augments Entry Driven by the Severe Acute Respiratory Syndrome Coronavirus Spike Protein. J Virol [Internet]. 2014;88:1293-307. Available from: https://journals.asm.org/doi/10.1128/JVI.02202-13

63. Hoffmann M, Kleine-Weber H, Schroeder S, Krüger N, Herrler T, Erichsen S, et al. SARS-CoV-2 Cell

Entry Depends on ACE2 and TMPRSS2 and Is Blocked by a Clinically Proven Protease Inhibitor. Cell

[Internet]. 2020;181:271-280.e8. Available from:

https://linkinghub.elsevier.com/retrieve/pii/S0092867420302294

64. Hoffmann M, Hofmann-Winkler H, Pöhlmann S. Priming Time: How Cellular Proteases Arm Coronavirus Spike Proteins. Act Viruses by Host Proteases [Internet]. Cham: Springer International Publishing; 2018. p. 71-98. Available from: http://link.springer.com/10.1007/978-3-319-75474-1_4

65. Yeung ML, Teng JLL, Jia L, Zhang C, Huang C, Cai J-P, et al. Soluble ACE2-mediated cell entry of SARSCoV-2 via interaction with proteins related to the renin-angiotensin system. Cell [Internet].

2021;184:2212-2228.e12. Available from:

https://linkinghub.elsevier.com/retrieve/pii/S009286742100283X 
66. Lundström A, Ziegler L, Havervall S, Rudberg A, Meijenfeldt F, Lisman T, et al. Soluble angiotensinconverting enzyme 2 is transiently elevated in COVID-19 and correlates with specific inflammatory and endothelial markers. J Med Virol [Internet]. 2021;93:5908-16. Available from:

https://onlinelibrary.wiley.com/doi/10.1002/jmv.27144

67. Epelman S, Tang WHW, Chen SY, Van Lente F, Francis GS, Sen S. Detection of Soluble AngiotensinConverting Enzyme 2 in Heart Failure. J Am Coll Cardiol [Internet]. 2008;52:750-4. Available from: https://linkinghub.elsevier.com/retrieve/pii/S0735109708020457

68. Driscoll WS, Vaisar T, Tang J, Wilson CL, Raines EW. Macrophage ADAM17 Deficiency Augments CD36-Dependent Apoptotic Cell Uptake and the Linked Anti-Inflammatory Phenotype. Circ Res [Internet]. 2013;113:52-61. Available from:

https://www.ahajournals.org/doi/10.1161/CIRCRESAHA.112.300683

69. Schweigert O, Dewitz C, Möller-Hackbarth K, Trad A, Garbers C, Rose-John S, et al. Soluble T cell immunoglobulin and mucin domain (TIM)-1 and -4 generated by A Disintegrin And Metalloprotease (ADAM)-10 and -17 bind to phosphatidylserine. Biochim Biophys Acta - Mol Cell Res [Internet]. 2014;1843:275-87. Available from: https://linkinghub.elsevier.com/retrieve/pii/S0167488913004060 70. de Queiroz TM, Lakkappa N, Lazartigues E. ADAM17-Mediated Shedding of Inflammatory Cytokines in Hypertension. Front Pharmacol [Internet]. 2020;11. Available from:

https://www. frontiersin.org/article/10.3389/fphar.2020.01154/full

71. Tajbakhsh A, Gheibi Hayat SM, Butler AE, Sahebkar A. Effect of soluble cleavage products of important receptors/ligands on efferocytosis: Their role in inflammatory, autoimmune and cardiovascular disease. Ageing Res Rev [Internet]. 2019;50:43-57. Available from:

https://linkinghub.elsevier.com/retrieve/pii/S1568163718302824

72. Schönrich G, Raftery MJ. The PD-1/PD-L1 Axis and Virus Infections: A Delicate Balance. Front Cell Infect Microbiol [Internet]. 2019;9. Available from:

https://www. frontiersin.org/article/10.3389/fcimb.2019.00207/full

73. Sharpe AH, Pauken KE. The diverse functions of the PD1 inhibitory pathway. Nat Rev Immunol [Internet]. 2018;18:153-67. Available from: http://www.nature.com/articles/nri.2017.108

74. Orme JJ, Jazieh KA, Xie T, Harrington S, Liu X, Ball M, et al. ADAM10 and ADAM17 cleave PD-L1 to mediate PD-(L)1 inhibitor resistance. Oncoimmunology [Internet]. 2020;9. Available from: https://www.tandfonline.com/doi/full/10.1080/2162402X.2020.1744980

75. Zhu X, Lang J. Soluble PD-1 and PD-L1: predictive and prognostic significance in cancer. Oncotarget [Internet]. 2017;8:97671-82. Available from:

https://www.oncotarget.com/lookup/doi/10.18632/oncotarget.18311

76. Bailly C, Thuru X, Quesnel B. Soluble Programmed Death Ligand-1 (SPD-L1): A Pool of Circulating Proteins Implicated in Health and Diseases. Cancers (Basel) [Internet]. 2021;13:3034. Available from: https://www.mdpi.com/2072-6694/13/12/3034

77. Sabbatino F, Conti V, Franci G, Sellitto C, Manzo V, Pagliano P, et al. PD-L1 Dysregulation in COVID-19 Patients. Front Immunol [Internet]. 2021;12. Available from:

https://www.frontiersin.org/articles/10.3389/fimmu.2021.695242/full

78. dos-Santos D et al. Efferocytosis of SARS-CoV-2-infected dying cells impairs macrophage antiinflammatory programming and continual clearance of apoptotic cells. MedRixv. 2021; Doi:

$10.1101 / 2021.02 .18 .21251504$

79. Gupta S, Hayek SS, Wang W, Chan L, Mathews KS, Melamed ML, et al. Factors Associated With Death in Critically III Patients With Coronavirus Disease 2019 in the US. JAMA Intern Med [Internet]. 2020;180:1436. Available from:

https://jamanetwork.com/journals/jamainternalmedicine/fullarticle/2768602

80. Sandoval M, Nguyen DT, Vahidy FS, Graviss EA. Risk factors for severity of COVID-19 in hospital patients age 18-29 years. Zivkovic AR, editor. PLoS One [Internet]. 2021;16:e0255544. Available from: https://dx.plos.org/10.1371/journal.pone.0255544 
81. Burrage DR, Koushesh S, Sofat N. Immunomodulatory Drugs in the Management of SARS-CoV-2. Front Immunol [Internet]. 2020;11. Available from:

https://www. frontiersin.org/article/10.3389/fimmu.2020.01844/full

82. The RECOVERY Collaborative Group. Dexamethasone in Hospitalized Patients with Covid-19. N Engl J Med [Internet]. 2021;384:693-704. Available from: http://www.nejm.org/doi/10.1056/NEJMoa2021436 83. McColl A, Bournazos S, Franz S, Perretti M, Morgan BP, Haslett C, et al. Glucocorticoids Induce Protein S-Dependent Phagocytosis of Apoptotic Neutrophils by Human Macrophages. J Immunol [Internet]. 2009;183:2167-75. Available from: http://www.jimmunol.org/lookup/doi/10.4049/jimmunol.0803503 84. Ehrchen J, Steinmuiller L, Barczyk K, Tenbrock K, Nacken W, Eisenacher M, et al. Glucocorticoids induce differentiation of a specifically activated, anti-inflammatory subtype of human monocytes. Blood [Internet]. 2007;109:1265-74. Available from: https://ashpublications.org/blood/article/109/3/1265/23908/Glucocorticoids-induce-differentiation-of-a 85. Lauber K, Keppeler H, Munoz LE, Koppe U, Schröder K, Yamaguchi H, et al. Milk fat globule-EGF factor 8 mediates the enhancement of apoptotic cell clearance by glucocorticoids. Cell Death Differ [Internet]. 2013;20:1230-40. Available from: http://www.nature.com/articles/cdd201382

86. Fernandez-Boyanapalli RF, Falcone EL, Zerbe CS, Marciano BE, Frasch SC, Henson PM, et al. Impaired efferocytosis in human chronic granulomatous disease is reversed by pioglitazone treatment. J Allergy Clin Immunol [Internet]. 2015;136:1399-1401.e3. Available from: https://linkinghub.elsevier.com/retrieve/pii/S0091674915010945 87. Erol A. Role of oxidized LDL-induced "trained macrophages" in the pathogenesis of COVID-19 and benefits of pioglitazone: A hypothesis. Diabetes Metab Syndr Clin Res Rev [Internet]. 2020;14:713-4. Available from: https://linkinghub.elsevier.com/retrieve/pii/S1871402120301260 88. Zizzo G, Cohen PL. The PPAR- $\gamma$ antagonist GW9662 elicits differentiation of M2c-like cells and upregulation of the MerTK/Gas6 axis: a key role for PPAR- $\gamma$ in human macrophage polarization. J Inflamm [Internet]. 2015;12:36. Available from: http://www.journal-inflammation.com/content/12/1/36 89. Fernandez-Boyanapalli R, Frasch SC, Riches DWH, Vandivier RW, Henson PM, Bratton DL. PPAR activation normalizes resolution of acute sterile inflammation in murine chronic granulomatous disease. Blood [Internet]. 2010;116:4512-22. Available from:

https://ashpublications.org/blood/article/116/22/4512/107845/PPAR $\gamma$-activation-normalizes-resolutionof-acute

90. Agrawal S, Chanley MA, Westbrook D, Nie X, Kitao T, Guess AJ, et al. Pioglitazone Enhances the Beneficial Effects of Glucocorticoids in Experimental Nephrotic Syndrome. Sci Rep [Internet].

2016;6:24392. Available from: http://www.nature.com/articles/srep24392

91. Calligaris M, Cuffaro D, Bonelli S, Spanò DP, Rossello A, Nuti E, et al. Strategies to Target ADAM17 in Disease: From Its Discovery to the iRhom Revolution. Molecules [Internet]. 2021;26:944. Available from: https://www.mdpi.com/1420-3049/26/4/944

92. Lartey NL, et al. ADAM17 inhibition prevents neutrophilia and lung injury in a mouse model of Covid-19. bioRxiv Prepr. 2021;Doi: 10.1101/2021.04.10.439288

93. Blaydon DC, Biancheri P, Di W-L, Plagnol V, Cabral RM, Brooke MA, et al. Inflammatory Skin and Bowel Disease Linked to ADAM17 Deletion. N Engl J Med [Internet]. 2011;365:1502-8. Available from: http://www.nejm.org/doi/abs/10.1056/NEJMoa1100721

94. Bandsma RHJ, van Goor H, Yourshaw M, Horlings RK, Jonkman MF, Schölvinck EH, et al. Loss of ADAM17 is associated with severe multiorgan dysfunction. Hum Pathol [Internet]. 2015;46:923-8. Available from: https://linkinghub.elsevier.com/retrieve/pii/S0046817715000763

95. Monteil V, Kwon H, Prado P, Hagelkrüys A, Wimmer RA, Stahl M, et al. Inhibition of SARS-CoV-2 Infections in Engineered Human Tissues Using Clinical-Grade Soluble Human ACE2. Cell [Internet]. 2020;181:905-913.e7. Available from: https://linkinghub.elsevier.com/retrieve/pii/S0092867420303998

96. Rahman MM, Hasan M, Ahmed A. Potential detrimental role of soluble ACE2 in severe COVID-19 comorbid patients. Rev Med Virol [Internet]. 2021;rmv.2213. Available from: 
https://onlinelibrary.wiley.com/doi/10.1002/rmv.2213

97. Zoufaly A, Poglitsch M, Aberle JH, Hoepler W, Seitz T, Traugott M, et al. Human recombinant soluble ACE2 in severe COVID-19. Lancet Respir Med [Internet]. 2020;8:1154-8. Available from:

https://linkinghub.elsevier.com/retrieve/pii/S2213260020304185

98. Belzile O, Huang X, Gong J, Carlson J, Schroit A, Brekken R, et al. Antibody targeting of

phosphatidylserine for the detection and immunotherapy of cancer. ImmunoTargets Ther [Internet].

2018;Volume 7:1-14. Available from: https://www.dovepress.com/antibody-targeting-of-

phosphatidylserine-for-the-detection-and-immunot-peer-reviewed-article-ITT

99. Dowall SD, Graham VA, Corbin-Lickfett K, Empig C, Schlunegger K, Bruce CB, et al. Effective Binding of a Phosphatidylserine-Targeting Antibody to Ebola Virus Infected Cells and Purified Virions. J Immunol Res [Internet]. 2015;2015:1-9. Available from: http://www.hindawi.com/journals/jir/2015/347903/

100. Soares MM, King SW, Thorpe PE. Targeting inside-out phosphatidylserine as a therapeutic strategy for viral diseases. Nat Med [Internet]. 2008;14:1357-62. Available from:

http://www.nature.com/articles/nm.1885

101. Bevers EM, Janssen MP, Comfurius P, Balasubramanian K, Schroit AJ, Zwaal RFA, et al. Quantitative determination of the binding of $\beta 2$-glycoprotein I and prothrombin to phosphatidylserine-exposing blood platelets. Biochem J [Internet]. 2005;386:271-9. Available from:

https://portlandpress.com/biochemj/article/386/2/271/78665/Quantitative-determination-of-thebinding-of

102. Ho Y, Ahuja K, Körner H, Adams M. $\beta 2 \mathrm{GP1}$, Anti- $\beta 2 \mathrm{GP1}$ Antibodies and Platelets: Key Players in the Antiphospholipid Syndrome. Antibodies [Internet]. 2016;5:12. Available from:

http://www.mdpi.com/2073-4468/5/2/12

103. Thomas JM, Thorpe PE. Protective Effect of Anti-Phosphatidylserine Antibody in a Guinea Pig Model of Advanced Hemorrhagic Arenavirus Infection. Open Microbiol J [Internet]. 2017;11:303-15. Available from: https://openmicrobiologyjournal.com/VOLUME/11/PAGE/303/

104. Shao R, Xiong C, Wen X, Gelovani JG, Li C. Targeting Phosphatidylserine on Apoptotic Cells with Phages and Peptides Selected from a Bacteriophage Display Library. Mol Imaging [Internet].

2007;6:7290.2007.00037. Available from: http://journals.sagepub.com/doi/10.2310/7290.2007.00037

105. Napoli. MCMRAASCDR Di. Features, Evaluation, and Treatment of Coronavirus (COVID-19). StatPearls [Internet] Treasure Isl StatPearls Publ [Internet]. In: StatPe. 2021; Available from:

https://www.ncbi.nlm.nih.gov/books/NBK554776/

106. Kern DM, Sorum B, Mali SS, Hoel CM, Sridharan S, Remis JP, et al. Cryo-EM structure of SARS-CoV-2 ORF3a in lipid nanodiscs. Nat Struct Mol Biol [Internet]. 2021;28:573-82. Available from:

http://www.nature.com/articles/s41594-021-00619-0

107. Gupta S, et al. D155Y Substitution of SARS-CoV-2 ORF3a Weakens Binding with Caveolin-1: An in

silico Study, bioRxiv Prepr. 2021; Doi: 10.1101/2021.03.26.437194

108. Padhan K, Tanwar C, Hussain A, Hui PY, Lee MY, Cheung CY, et al. Severe acute respiratory

syndrome coronavirus Orf3a protein interacts with caveolin. J Gen Virol [Internet]. 2007;88:3067-77.

Available from: https://www.microbiologyresearch.org/content/journal/jgv/10.1099/vir.0.82856-0

109. Chakraborty S, Mallajosyula V, Tato CM, Tan GS, Wang TT. SARS-CoV-2 vaccines in advanced clinical

trials: Where do we stand? Adv Drug Deliv Rev [Internet]. 2021;172:314-38. Available from:

https://linkinghub.elsevier.com/retrieve/pii/S0169409X21000247

110. Caddy SL, Vaysburd M, Papa G, Wing M, O'Connell K, Stoycheva D, et al. Viral nucleoprotein

antibodies activate TRIM21 and induce T cell immunity. EMBO J [Internet]. 2021;40. Available from:

https://onlinelibrary.wiley.com/doi/10.15252/embj.2020106228

111. Kunzelmann K. Getting hands on a drug for Covid-19: Inhaled and Intranasal Niclosamide. Lancet

Reg Heal - Eur [Internet]. 2021;4:100094. Available from:

https://linkinghub.elsevier.com/retrieve/pii/S2666776221000715 

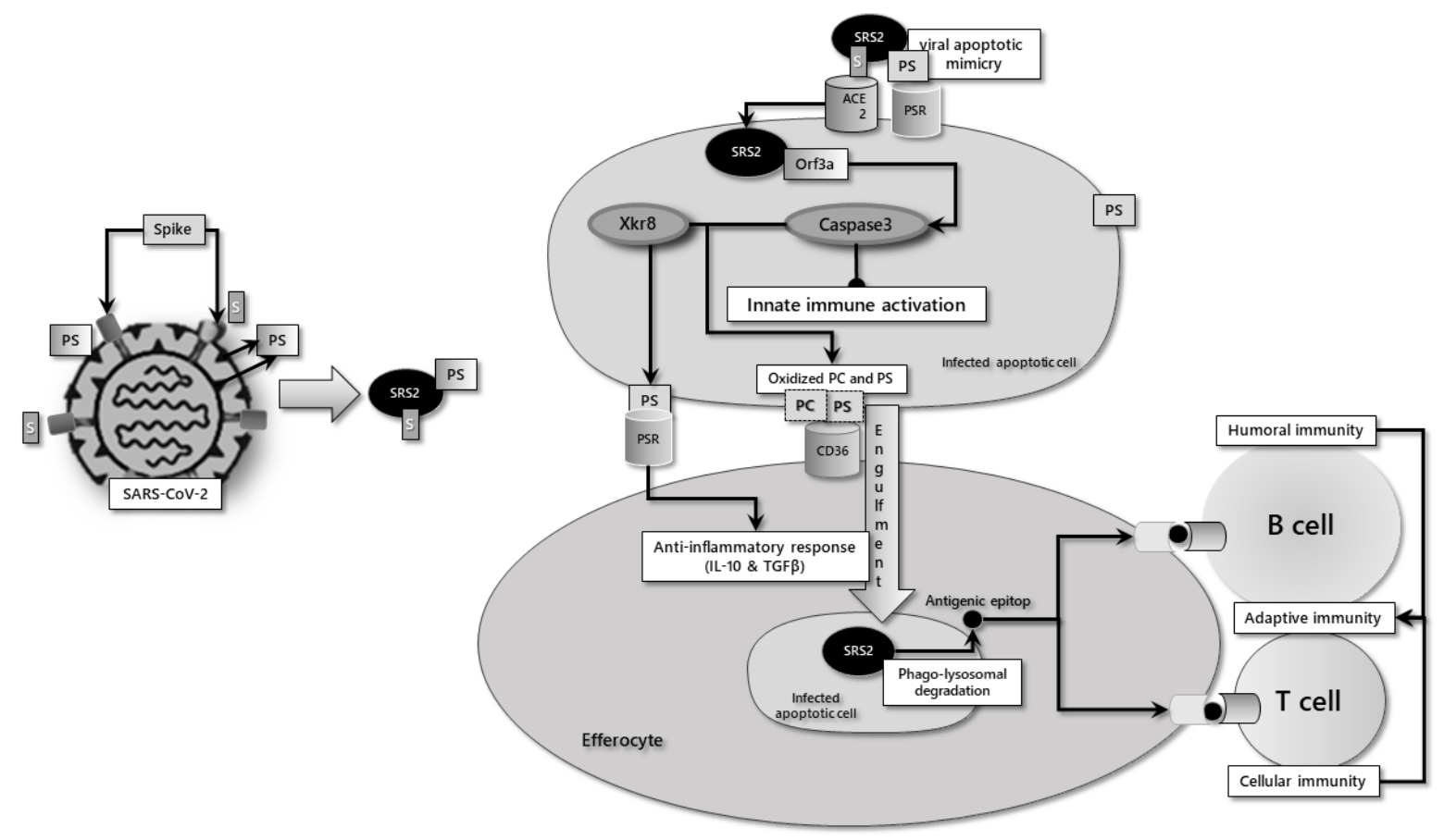

Figure 1. Simplified depiction of the apoptotic/efferocytic process in SARS-COV-2 infection. The phosphatidylserine (PS) in the envelope of the virus attaches to the PS receptors (PSRs) on the target cell, facilitating the binding of the viral spike protein to the host ACE2 receptor. In the cell, the viral ORF3a protein initiates the apoptotic process by the caspase- 3 activation. While activated caspase-3 inhibits cellular innate immune response, caspase-3-driven permanent activation of the Xkr8 scramblase causes PS expression in the membrane outer leaflet of apoptotic cells. Caspase-3 also oxidizes PS and phosphatidylcholine (PC). PS binds to efferocytic cells via PSRs, facilitating the binding of oxidized PC and PS to CD36 and engulfment of the apoptotic cell. Successfully induced efferocytosis is a sterile process with the secretion of anti-inflammatory mediators. In addition, antigenic viral epitopes, which arise due to phago-lysosomal degradation of the virus in antigen-presenting cells, can initiate T- and B-cellmediated adaptive immunity. 


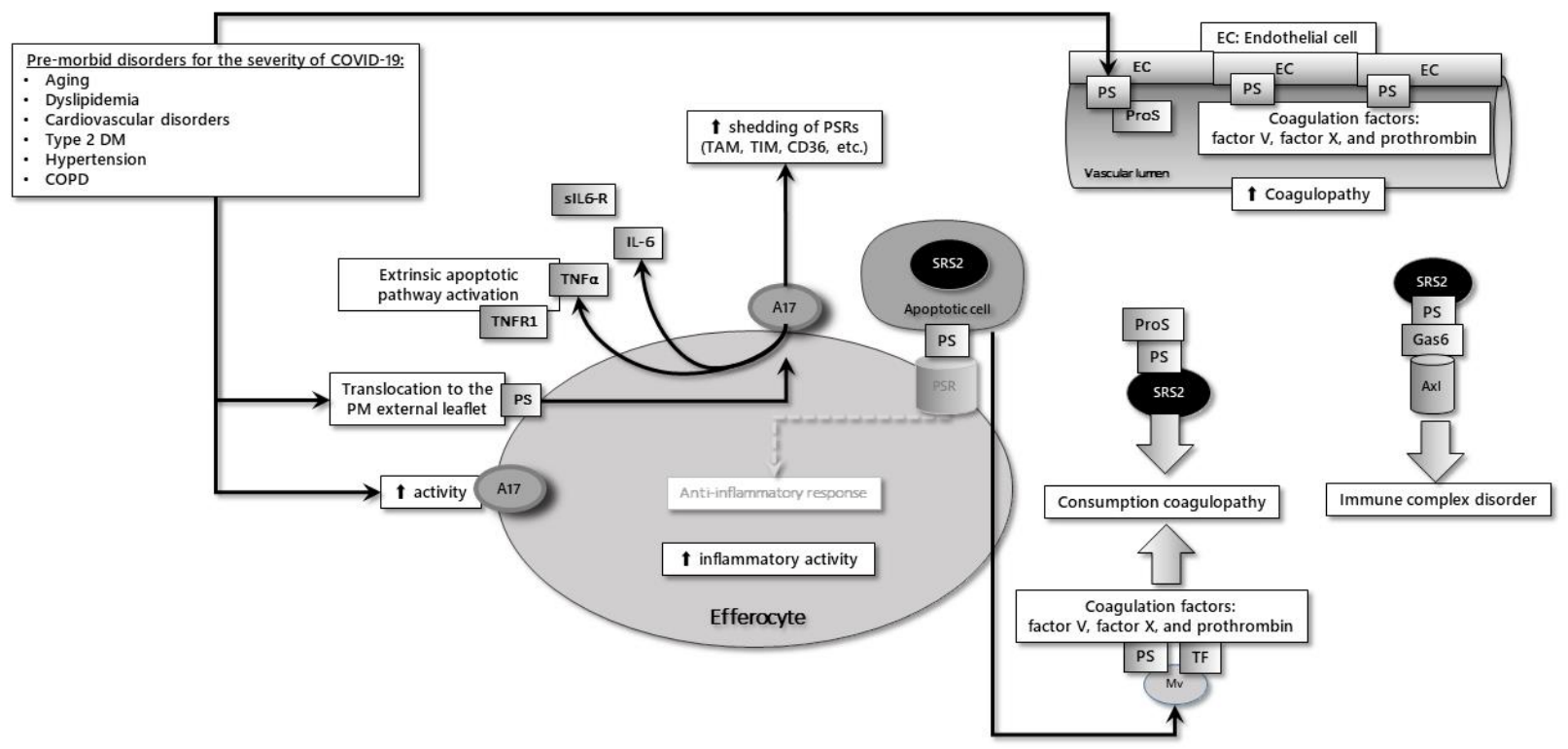

Figure 2. The common characteristics of co-morbid diseases responsible for the severity of COVID-19 are increased PS expression and ADAM-17 (A17) activity in cells. ADAM-17 renders efferocytosis as defective due to the shedding of the receptors required for the engulfment of apoptotic cells. PS expressed on the surface of endothelial cells, PS in the SARS-COV-2 envelope, and microvesicles (Mv) detached from apoptotic cells reason in coagulopathy seen in COVID-19. 